\title{
Insight into the environmental monitoring and source apportionment of volatile organic compounds (VOCs) in various functional areas
}

\author{
Shuibing Wang ${ }^{1,2} \cdot$ Guijian Liu ${ }^{1} \cdot \mathrm{Hong} \mathrm{Zhang}^{2} \cdot$ Mingjian $\mathrm{Yi}^{3} \cdot$ Yuan Liu $^{1} \cdot \mathrm{Xingyuan} \mathrm{Hong}^{2} \cdot \mathrm{Xiang} \mathrm{Bao}^{2}$
}

Received: 29 March 2021 / Accepted: 5 September 2021 / Published online: 6 October 2021

(C) The Author(s) 2021

\begin{abstract}
Atmospheric aerosol contamination has caused widespread concern about human and environmental health. However, research about VOCs as an important precursor of secondary aerosols in ambient air is still limited. In this study, VOCs at sites from three typical functional areas in Hefei, China, were monitored using GC-MS/FID. The VOCs in ambient air from different functional areas showed significantly different characteristics. The highest concentrations and the biggest diurnal difference of VOCs were found in the High-tech Zone (industrial area) with serried emission sources. Additionally, lower VOC concentration was observed in Changjiang West Road, the center area of studied city. The VOC concentration in this area is strongly related to other pollutants. The composition of VOCs at all sampling sites showed certain common characteristics, i.e., alkanes, OVOCs, and halogenated hydrocarbons account for more than $75 \%$ of the total VOCs' quality. The High-tech Zone with the highest concentration of VOCs also has the highest proportion of alkanes. Besides, the positive matrix factorization analysis results revealed that vehicle exhaust, LPG volatilization sources, and chemical solvents were the most important VOC emission sources in Hefei. In terms of the contribution of VOC components to the OFP at the three sites, the olefins and alkynes at the Changiiang West Road site and the Science Island site contribute the most significant proportion. In contrast, the OVOCs at the High-tech Zone site contribute the largest proportion.
\end{abstract}

Keywords VOCs $\cdot$ Monitoring $\cdot$ Source appointment $\cdot$ Functional areas

\section{Introduction}

VOCs are important precursors of ozone and secondary aerosols in ambient air (Hatfield and Huff Hartz 2011; He et al. 2019). The increase of VOCs is one of the primary reasons for declining air quality and photochemical contamination (Baudic et al. 2016; Yue et al. 2017). In recent years, atmospheric environmental protection control measures are mainly focused on reducing the concentration of particulate matter

Guijian Liu

lgj@ustc.edu.cn

Mingjian Yi

mjyi@ustc.edu.cn

1 CAS Key Laboratory of Crust-Mantle Materials and the Environments, School of Earth and Space Sciences, University of Science and Technology of China, Hefei 230026, China

2 Anhui Research Academy of Environmental Sciences, Hefei 230600, China

3 Anhui Jianzhu University, Hefei 230600, China in China (Zeng et al. 2019). However, the emission and conversion of VOCs have not attracted enough attention. The air qualities of 337 cities across China have been continuously improved for six consecutive years, but ozone pollution is still worsening under overall improvement in air quality ( $\mathrm{Li}$ et al. 2019a; Ma et al. 2016; Zeng et al. 2019). To relieve the ozone pollution problem, the characteristics and sources of precursors such as VOCs related to ozone formation should be further studied to support formulating treatments.

In eastern China, the increase of ozone concentration in summer has attracted the attention of many researchers, and there are many different views on the causes of increased ozone pollution. Dang et al. (2021) believed that the increase of ozone in summer is related to meteorological factors such as weak wind speed and low humidity. However, more studies have shown that meteorological factors have not significantly impacted on the long-term changes of ozone (Ma et al. 2016). By deducting the impact of meteorological changes, some researchers calculated that the increase in ozone in megacities from eastern China was mainly due to changes in source emissions (Cheng et al. 2019; Li et al. 
2019a). The reaction of VOCs and NOx balance mechanism is the key to influence the ozone concentration (Shao et al. 2009; Zou et al. 2015). Among them, some researchers believe that the decrease of NOx emissions is the reason for the increasing ozone ( $\mathrm{Li}$ et al. 2019b), but more research results indicate that the increase of high concentration of VOC emissions caused by the rapid development of industrialization is the most important factor. In addition, some researchers have proposed that the decrease of $\mathrm{PM}_{2.5}$ may cause the rise in ozone, because $\mathrm{PM}_{2.5}$ can remove $\mathrm{HO} 2$ and NOx (Li et al. 2019b). When $\mathrm{PM}_{2.5}$ is low, this removal mechanism becomes weaker, which may increase ozone. Based on the continuous decline of $\mathrm{PM}_{2.5}$ concentration and rising ozone concentration in China in recent years, the task of controlling VOC emissions is particularly urgent. Monitoring and research on ambient air quality during the Hangzhou $\mathrm{G}_{20}$ meeting also found that reducing NOx and VOCs can reduce the concentration of $\mathrm{O}_{3}$, which is sensitive to the reduction of emissions from the industrial, power, residential, and transportation sectors (Wang and Liao 2020).

However, the components of VOCs are complex, and different cities have their own characteristics (Hatfield and Huff Hartz 2011; Li et al. 2021; Liu et al. 2016). Reactive olefins (such as isoprene and cis-2-butene) are regarded as the main ingredient that influences the formation of $\mathrm{O}_{3}$ in Zhengzhou from Central China (Li et al. 2021), while isoprene, formaldehyde, xylene, and trimethyl-benzene are the significant substances that regulate the formation of local $\mathrm{O}_{3}$ in the Pearl River Estuary (Liu et al. 2021). The main sources of VOCs from Wuhan are industrial sources, automobile exhaust and liquefied petroleum gas, and olefins that contribute most to the formation of $\mathrm{O}_{3}$ (Hui et al. 2018, 2019). Due to the diversity of VOC composition, understanding VOC composition and other city characteristics is preparatory work to carry out ozone pollution prevention and control. In addition, as pointed out by Niu et al. (2021), the environmental temperature changes in different seasons can significantly affect the mass percentage of VOC types, increasing the uncertainty of the impact of VOCs on $\mathrm{O}_{3}$. Therefore, field monitoring and component analysis of VOCs in Hefei during ozone pollution season are particularly important for understanding ozone pollution in the city.

\section{Materials and methods}

\section{Sample collection}

Three representative sites were selected in the main urban area of Hefei: Changjiang West Road, Science Island, and the High-tech Zone, respectively, as shown in Fig. 1. The Changjiang West Road site is located in the center of Hefei (commercial and residential areas). The Science Island site is located in the northwest of the city (science and education area). Surrounded by water on three sides and shaded by trees, the island is adjacent to one extensive reservoir, and many scientific research institutes are distributed on the island. The High-tech Zone (industrial area) site is located in the High-tech Development Zone in the city's southwest. The specific point position is located in the factory area with busy freight vehicles, surrounded by numerous enterprises.

The sampling time in this study was from July to December 2019 (109 days in total). The sampling time of the Changjiang West Road site is from July 25 to September 8 (46 days), from October 5 to November 5 (32 days) for the Science Island site, and from November 7 to December 7 (31 days) for the High-tech Zone site. Multi-channel online GC-MS/FID which can measure more than 117 types of VOCs was used for sampling and monitoring. The equipment mainly includes an ultra-low temperature preconcentration system and sample injection device. The measure resolution of time is $60 \mathrm{~min}$.

\section{Methods}

Positive matrix factorization (PMF) model (Norris et al. 2014), ozone generation potential (OFP), and secondary organic aerosol (SOA) analysis methods are used to analyze the source of VOCs in Hefei.

The basic formulas for PMF calculation are as follows:

$E_{i k}=\sum_{j=1}^{p} A_{i j} B_{j k}+\varepsilon_{i k}(i=1,2, \cdots, n)$

where $E_{i k}$ is the concentration of pollutant $i$ observed at the $k$ th time; $j$ is the factor; and $A_{i j}$ and $B_{j k}$ are the source component spectrum and source contribution, respectively. $\varepsilon_{i k}$ is residual. PMF is mainly used to calculate the minimum value of objective function $Q$, which is:

$Q=\sum_{i}^{m} \sum_{k}^{n}\left(\frac{\varepsilon_{i k}}{\sigma_{i k}}\right)^{2}$

OFP analysis method can be used to reflect $\mathrm{O}_{3}$ generation or loss caused by VOCs. Carter (1994) proposed the concept of maximum incremental reactivity (MIR) to evaluate the ability of VOC species to produce $\mathrm{O}_{3}$ through chemical reaction under ideal conditions, and the calculation formula is as follows:

$\mathrm{OFP}_{i}=\left[\mathrm{VOCs}_{i}\right] \times \mathrm{MIR}_{i}$

where $\mathrm{OFP}_{i}$ refers to the ozone generation potential of the $i$ th VOC species; MIR $_{i}$ refers to the maximum incremental reaction coefficient of the $i$ th VOC species, denoted by $\mathrm{O}_{3} /$ VOCs. 


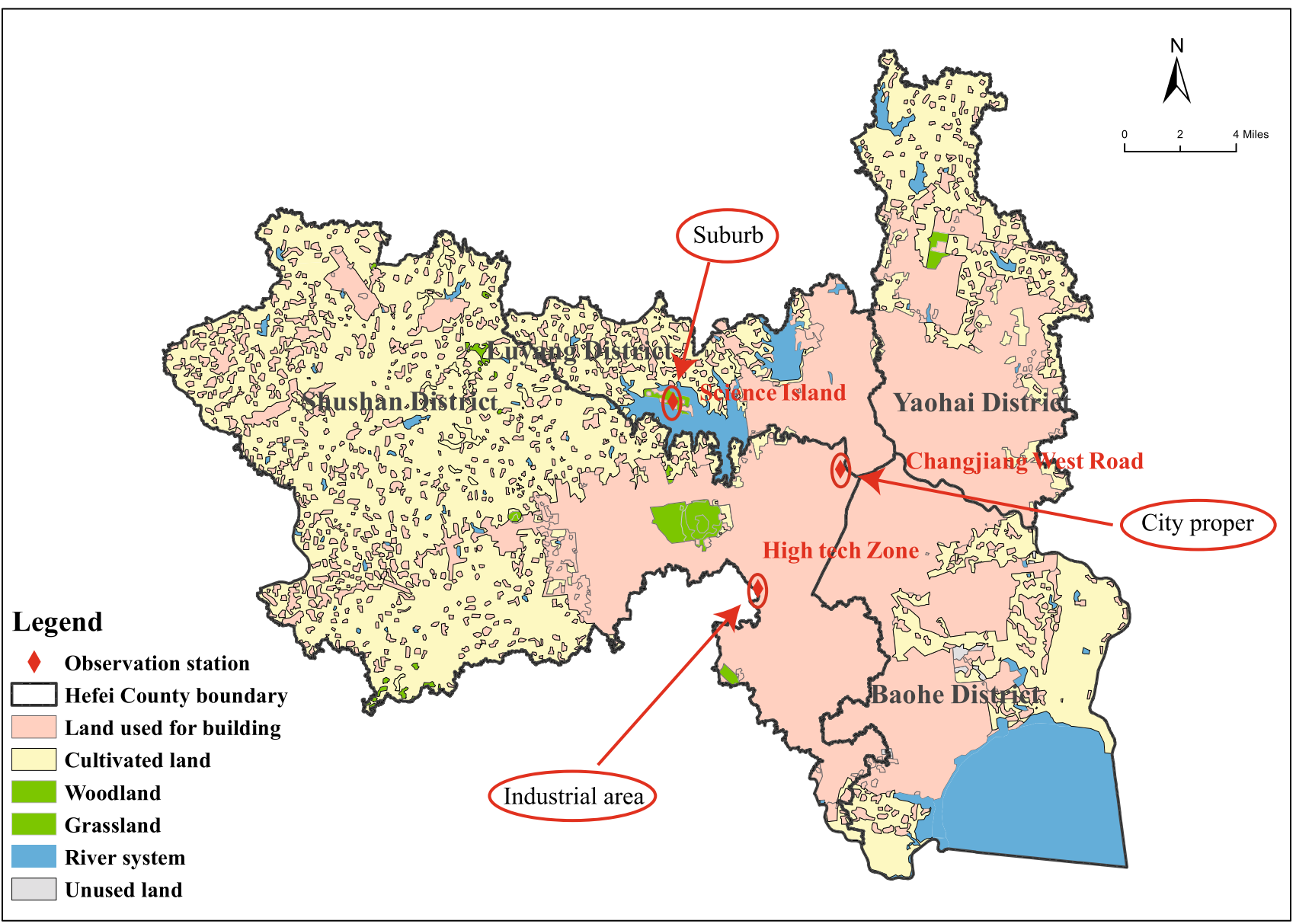

Fig. 1 Study area and sampling site map

The SOA analysis approach is used to assess the impact of VOCs in the ambient air on SOA generation. The aerosol generation coefficient method (FAC method) (Grosjean 1992; Grosjean and Seinfeld 1989) was used to evaluate the SOA generation potential in Hefei. The calculation formula is as follows:

$\mathrm{SOA}_{p}=\mathrm{VOCs}_{t} /\left(1-F_{\mathrm{VOCr}}\right) \times \mathrm{FAC}$

where $\mathrm{SOA}_{p}$ refers to the generation potential of SOA; $\mathrm{VOC}_{\mathrm{st}}$ refers to the concentration of VOCs in ambient air; $F_{\mathrm{VOCr}}$ refers to the SOA generation factor (\%); and $F_{\mathrm{VOCr}}$ and FAC were obtained by smoke chamber experiment.

\section{Results and discussion}

\section{Variation characteristics of total VOC concentration}

The total VOC (TVOC) concentrations obtained from three monitoring sites in Hefei were significantly different. The
TVOC concentrations measured in the High-tech Zone site were the highest, with an average of $106.05 \mu \mathrm{g} / \mathrm{m}^{3}$, which may be due to the combined effects of industrial emissions and motor vehicle exhaust (Mihriban et al., 2015). The TVOC concentrations measured at the Science Island site and the Changjiang West Road site were significantly lower than those at the High-tech Zone site, $68.79 \mu \mathrm{g} / \mathrm{m}^{3}$ and $56.92 \mu \mathrm{g} / \mathrm{m}^{3}$, respectively. As a referee, Yang et al. (2019) reported an annual-mean VOC concentration of $32.61 \mathrm{ppbv}$ (corresponding to $130 \mu \mathrm{g} / \mathrm{m}^{3}$ ) in Wuhan over a period of 1 year, higher than the average values during the monitoring period in Hefei. The TVOC concentrations at the Changjiang West Road site are strongly disturbed with time, followed by those at the High-tech Zone site, and the concentration at the Science Island site is weakly affected by time (Fig. 2a). For VOCs such as alkanes, alkenes, halogenated hydrocarbons, OVCs, and aromatic hydrocarbons, their concentrations over time were also different across the three sites (Fig. 2b). Among different VOCs, halogenated hydrocarbon, alkane, and OVCs have the most remarkable changes over time at the site of west Changjiang Road, High-tech Zone, 
Fig. 2 Temporal variation of atmospheric VOCs at three sites

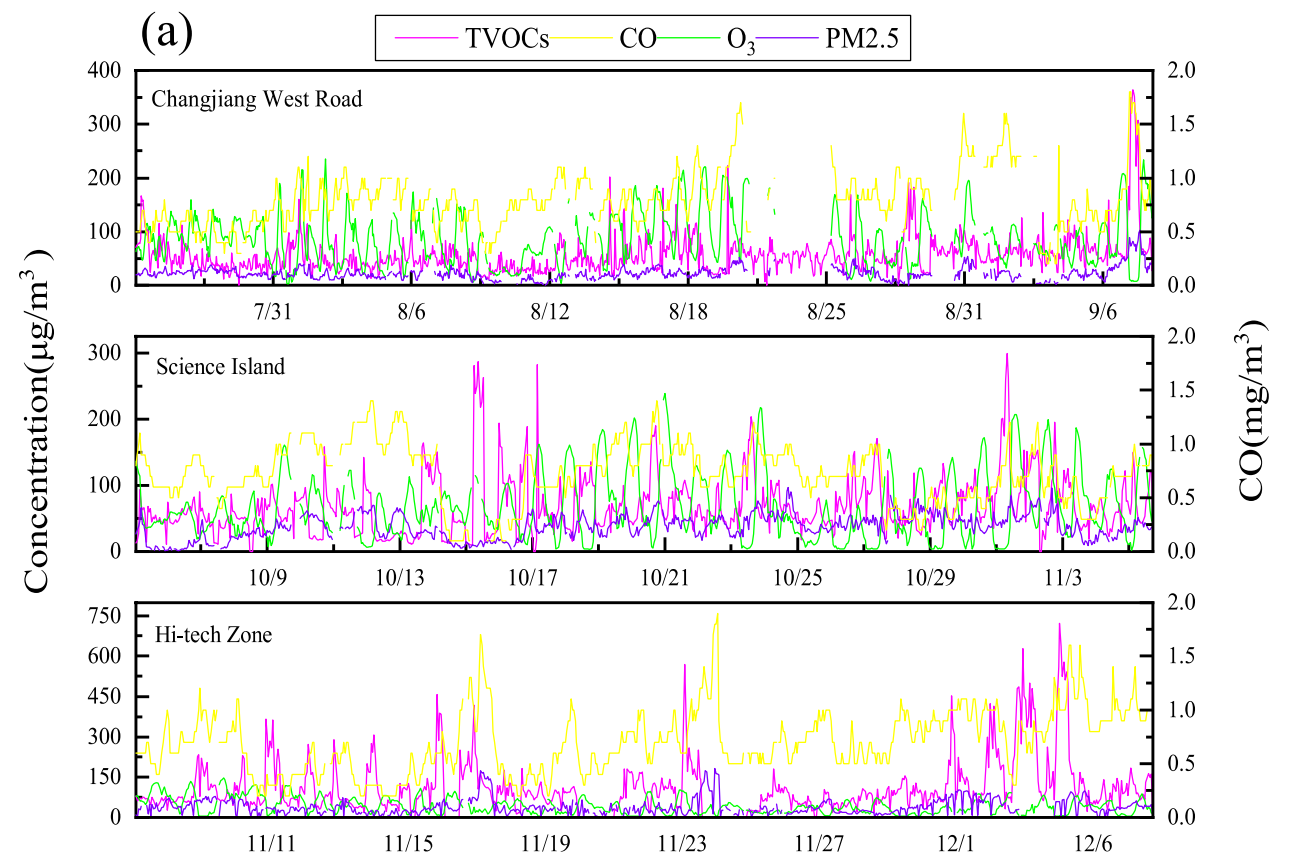

(b) — Alkane — Alkyne — Halohydrocarbon — OVCs — Aryl hydrocarbon

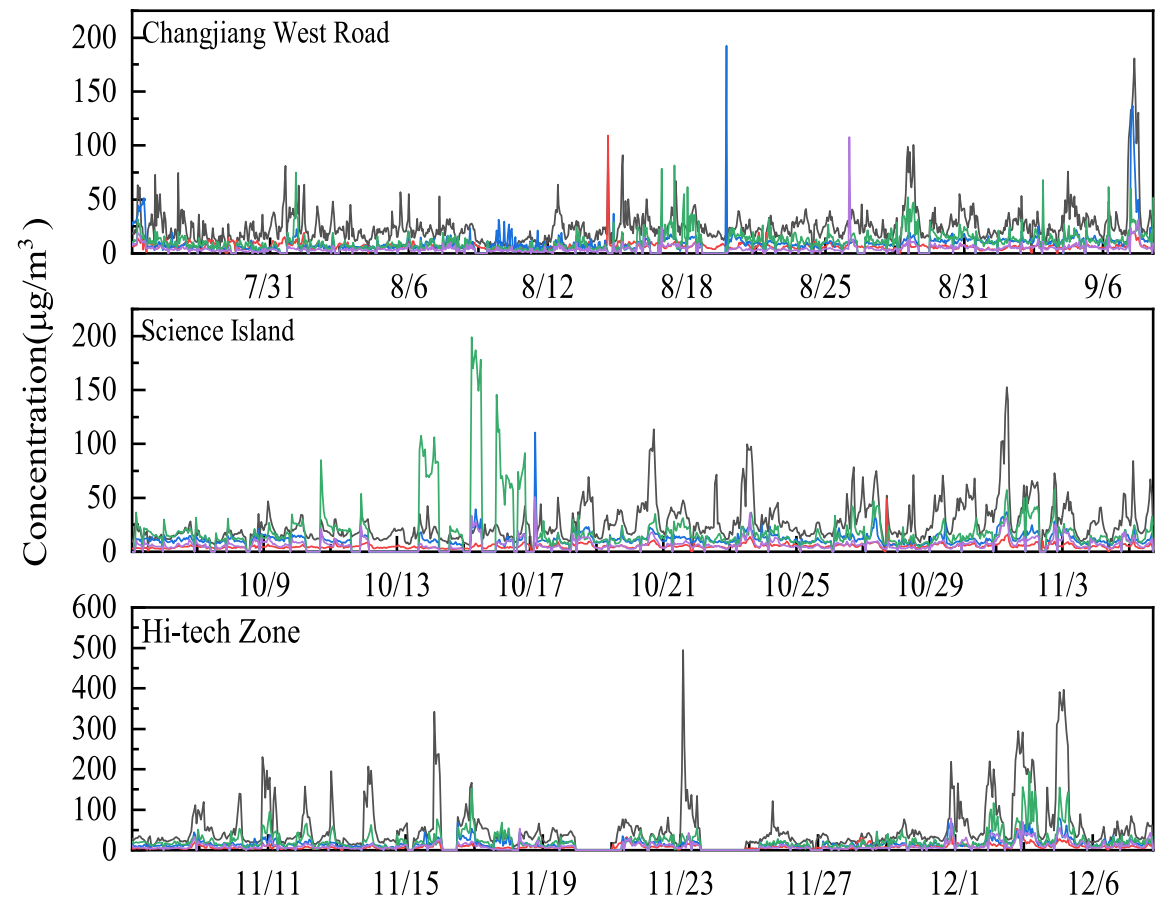

and Science Island, respectively. Alkanes and alkenes are the most important VOC components in Hefei urban air, consistent with the results in Wuhan (Yang et al. 2019) and Shanghai (Zhang et al. 2018).

In order to further analyze the specific characteristics of TVOCs at different monitoring sites over time and their correlation with other environmental pollutants, Fig. 2 shows the time change curves of TVOCs, $\mathrm{CO}, \mathrm{O}_{3}$, and $\mathrm{PM}_{2.5}$ at the three monitoring sites. The peak concentration of TVOCs in the High-tech Zone site is the highest. The concentration of more than $500 \mu \mathrm{g} / \mathrm{m}^{3}$ was detected several times, and the variation range of the concentration was extensive, with a relatively significant periodicity. The monitoring results of the Changjiang West Road site and the High-tech Zone site are obviously different. At the Changjiang West Road site, the TVOC concentration is relatively low and the variation range is small. The concentration of TVOCs in the Science 
Table 1 Correlation coefficients between TVOCs and other contaminants $\left(\mathrm{O}_{3}, \mathrm{CO}\right.$, and $\left.\mathrm{PM}_{2.5}\right)$

\begin{tabular}{lllll}
\hline Monitoring site & Contaminant & $\mathrm{CO}$ & $\mathrm{O}_{3}$ & $\mathrm{PM}_{2.5}$ \\
\hline Yangtze West Road & TVOCs & 0.41 & -0.18 & 0.48 \\
Science Island & TVOCs & 0.18 & -0.24 & 0.13 \\
High-tech Zone & TVOCs & 0.23 & -0.30 & 0.14 \\
\hline
\end{tabular}

The correlation was significant at 0.05 level

Island site is between other two location's values and shows moderate periodicity.

The correlation coefficients between TVOC concentration and $\mathrm{O}_{3}, \mathrm{CO}$, and $\mathrm{PM}_{2.5}$ are shown in Table 1. In general, $\mathrm{CO}$ in the ambient air is directly emitted, with almost no secondary generation. Hence, its concentration is used here as a marker for conditions associated with primary emissions and environmental diffusion. There are significantly positive correlations between TVOC concentration and CO, TVOCs, and $\mathrm{PM}_{2.5}$, and a significantly negative correlation between TVOC and $\mathrm{O}_{3}$ concentration. Among the three sites in Hefei, TVOCs at the Changjiang West Road site have the most significant correlation coefficient with $\mathrm{CO}$ and $\mathrm{PM}_{2.5}$. They have a significant commonality of temporal variation. The correlation coefficient between TVOCs and CO, TVOCs, and $\mathrm{PM}_{2.5}$ at the Science Island site is relatively small. The negative correlation between TVOCs and $\mathrm{O}_{3}$ in the Hightech Zone site is the most significant. We speculated that the Science Island site is located in the suburb. And therefore, the TVOC concentration mainly reflects the local concentration in the ambient air, and is weakly correlated with other factors. The emission intensity of TVOCs in high-tech zones is high, and the strong negative correlation with $\mathrm{O}_{3}$ indicates that the conversion of VOCs to $\mathrm{O}_{3}$ caused by photochemical reactions may be very important. In the urban center where the Yangtze West Road station is located, TVOC is correlated with $\mathrm{CO}$ and $\mathrm{PM}_{2.5}$ concentrations to some extent, potentially reflecting the mixed mechanism under complex emission conditions and diffusion process.

In order to further analyze the periodic characteristic of TVOCs, Fig. 3 shows the change curve (daily and weekly) of TVOC concentration. Three sites in Hefei have a typical daily variation trend, and the concentration curve of TVOCs presents a significant double peak. Similar observations were also mentioned by Yurdakul et al. (2018) and Zhang et al. (2018) for the ambient air in Bursa and Shanghai. In the morning ( $6 \mathrm{am}$ to $8 \mathrm{am}$ ) and in the evening ( $8 \mathrm{pm}$ to $10 \mathrm{pm}$ ), the two periods of 1 day reaches extremely high points. However, in the afternoon ( $1 \mathrm{pm}-3 \mathrm{pm})$, the concentration of TVOCs reaches a shallow point. The atmosphere is relatively stable in the morning and evening, and the convective motion is weak and the boundary layer is low, which is not conducive to the diffusion of TVOCs. At the same time, the morning and evening peaks are also affected by the traffic peaks, so the concentration of TVOCs is higher in the morning and evening. In the contrast, the strong convection at noon causes the boundary layer to rise, which is conducive to the dilution and mixing of TVOCs. And, the photochemical reaction also consumes a lot of TVOCs due to strong sunshine at noon (Wei et al. 2018). Therefore, the concentration is lower at noon. Comparing the three sites in Hefei, the daily variation of TVOC concentration in the High-tech Zone site is the most intense, the difference between the maximum and minimum of TVOC concentration is more than $100 \mu \mathrm{g} / \mathrm{m}^{3}$, and the high concentration is maintained for a long time at night. Similar diurnal variation characteristics were also found by Zou et al. (2015) in the monitoring study of VOCs in Guangzhou, but different from them, the minimum concentration of VOCs appeared at about 15 o'clock in a day in Hefei, which is a little earlier than that in Guangzhou. In addition, the late-night VOC concentration in Hefei has a significant decline, which is significantly different from that in Guangzhou. Among the other two sites, diurnal variation and concentration of TVOCs in the Science Island site is larger than that of the Changjiang West Road site. The weekly variation of TVOCs concentration at the three sites was not significant from the average weekly results. The TVOC concentration in the High-tech Zone fluctuates significantly. At the same time, TVOCs at the Science Island and Changjiang West Road sites maintain a relatively stable concentration, and there is no noticeable difference between working days and weekends.

Through the above comparison of the variation of VOC concentration at the three sites in Hefei, different characteristics can be found: The average concentration of VOCs in West Changjiang Road is low with weak diurnal variation and a strong correlation with the concentration of other pollutants. The average concentration of VOCs in the High-tech Zone is high, with significant daily variation and general correlation with the concentration of other pollutants. The mean concentration of VOCs at the Science Island site is low, the diurnal variation is small, and the correlation with other pollutant concentrations is weak. Changjiang West Road site is located in the center of the city, with few surrounding industrial enterprises, complex sources of pollution, and generally low emission intensity. It is greatly affected by local environmental and meteorological conditions in the city, and complex pollution is the most prominent characteristic. The High-tech Zone is a centralized economic industrial park with a large number of industrial enterprises and high emission intensity. The observed average concentration of TVOCs is high and the variation is large between day and night, which may be directly related to the existence of specific emission sources in the surrounding environment. The Science Island site is located in the suburb of the city, and its main functions are scientific research, education, and 

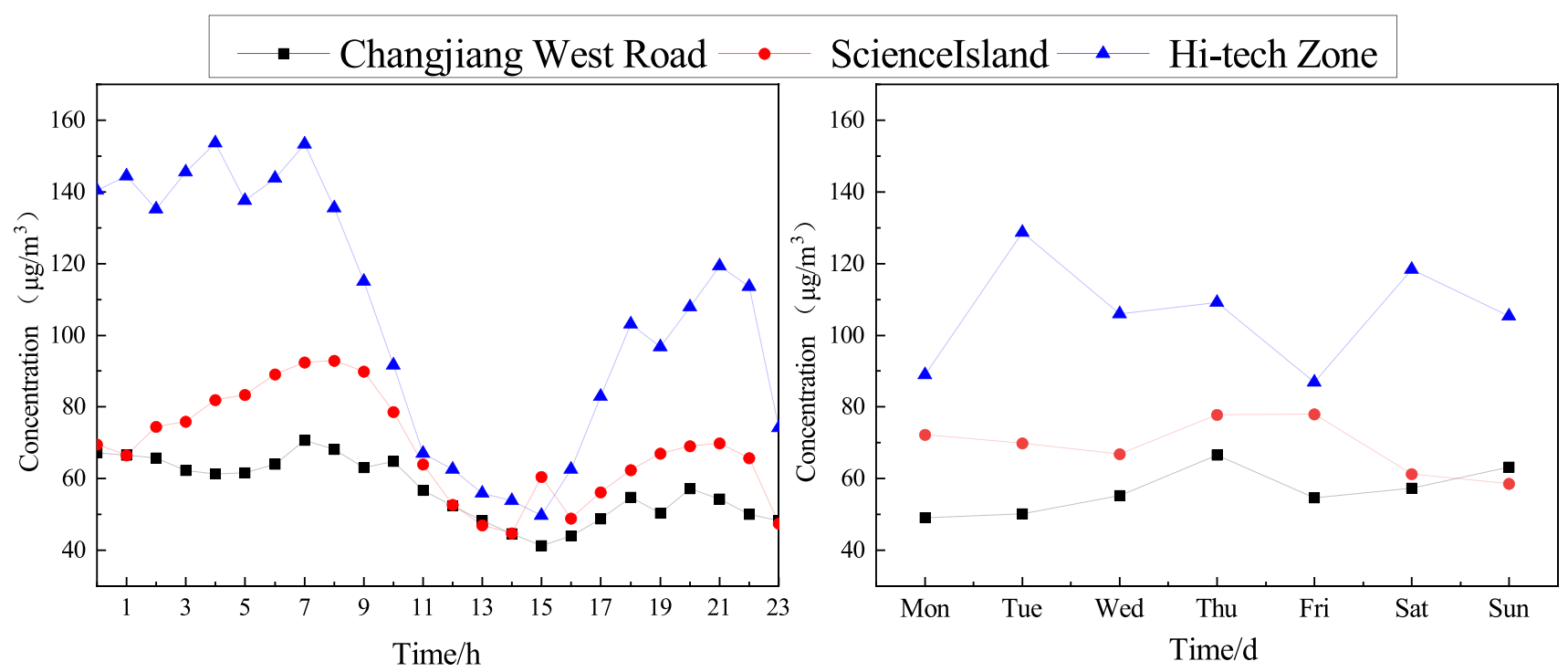

Fig. 3 Periodical variation of VOCs in three sites. a Daily average concentration. b Weekly average concentration

residence, etc. With a high rate of environmental greening, less industrial pollution, and relatively stable TVOC concentration, it can be compared with other sites on behalf of the background of the urban environment.

\section{Composition characteristics of atmospheric VOCs}

The statistical results of VOC composition at the three sites are shown in Fig. 4. At the Changjiang West Road site, it can be seen that alkane is the major component with the highest content, with an average hourly concentration of $24.96 \mu \mathrm{g} / \mathrm{m}^{3}$, accounting for $41.06 \%$ of TVOCs. The content of OVOCs ranks only second to alkane, and the average hourly concentration is $12.04 \mu \mathrm{g} / \mathrm{m}^{3}$, accounting for $19.81 \%$ of TVOCs. Halogenated hydrocarbons are the third component with an average hourly concentration of $10.69 \mu \mathrm{g} / \mathrm{m}^{3}$, accounting for $17.69 \%$ of TVOCs. The average hourly concentrations of olefin, aromatics, acetylene, and carbon disulfide were $6.72 \mu \mathrm{g} / \mathrm{m}^{3}, 4.85 \mu \mathrm{g} / \mathrm{m}^{3}$, $1.36 \mu \mathrm{g} / \mathrm{m}^{3}$, and $0.16 \mu \mathrm{g} / \mathrm{m}^{3}$, respectively, accounting for $11.05 \%, 7.99 \%, 2.24 \%$, and $0.26 \%$ of TVOCs.

Alkane is the component with the highest content in the Science Island site, and its average hourly concentration is $26.61 \mu \mathrm{g} / \mathrm{m}^{3}$, accounting for $34.68 \%$ of TVOCs. The content of OVOCs is second only to alkane, and the average hourly concentration is $22.28 \mu \mathrm{g} / \mathrm{m}^{3}$, accounting for $29.14 \%$ of TVOCs. Halogenated hydrocarbons are the third component with an average hourly concentration of $12.55 \mu \mathrm{g} / \mathrm{m}^{3}$, accounting for $16.42 \%$ of TVOCs. The average hourly concentrations of aromatic hydrocarbons, alkenes, acetylene, and carbon disulfide are $7.65 \mu \mathrm{g} / \mathrm{m}^{3}$,
$5.22 \mu \mathrm{g} / \mathrm{m}^{3}, 1.99 \mu \mathrm{g} / \mathrm{m}^{3}$, and $0.25 \mu \mathrm{g} / \mathrm{m}^{3}$, accounting for $10.01 \%, 6.83 \%, 2.60 \%$, and $0.32 \%$ of TVOCs, respectively.

Alkane in the High-tech Zone site is the component with the highest content, with an average hourly concentration of $56.67 \mu \mathrm{g} / \mathrm{m}^{3}$, accounting for $45.92 \%$ of TVOCs. Aromatics and alkene-dominated ambient VOCs are also found in Baoji, China (Xue et al. 2017). OVOC content is second only to alkane, and the average hourly concentration is $26.11 \mu \mathrm{g} /$ $\mathrm{m}^{3}$, accounting for $21.16 \%$ of TVOCs. Halogenated hydrocarbons are the third component with an average hourly concentration of $17.65 \mu \mathrm{g} / \mathrm{m}^{3}$, accounting for $14.30 \%$ of TVOCs. The average hourly concentrations of aromatic hydrocarbons, alkenes, acetylene, and carbon disulfide are $11.78 \mu \mathrm{g} /$ $\mathrm{m}^{3}, 8.50 \mu \mathrm{g} / \mathrm{m}^{3}, 2.24 \mu \mathrm{g} / \mathrm{m}^{3}$, and $0.46 \mu \mathrm{g} / \mathrm{m}^{3}$, accounting for $9.54 \%, 6.89 \%, 1.81 \%$, and $0.38 \%$ of TVOCs, respectively.

In conclusion, the observation results of VOC composition in Hefei showed that the top three VOC composition are alkane, OVOCs, and halogenated hydrocarbons, which account for more than $75 \%$ of the quality of TVOCs. The average proportion of alkanes in Hefei is about $40.7 \%$, which is close to the results in Wuhan and Shanghai. However, the average proportion of alkenes in Hefei is about $8.3 \%$, which is much lower than those in Wuhan $(13 \%)$ and Shanghai (17.9\%). The average proportion of OVOC in Hefei is second only to alkane hydrocarbons, accounting for about $23.4 \%$, which is completely different from the characteristics of the two cities mentioned above. The proportion of alkanes is the highest at the High-tech Zone site. The proportion of OVOCs is the highest at the Science Island site. The proportion of halogenated hydrocarbons is the highest at the Changjiang West Road site. 

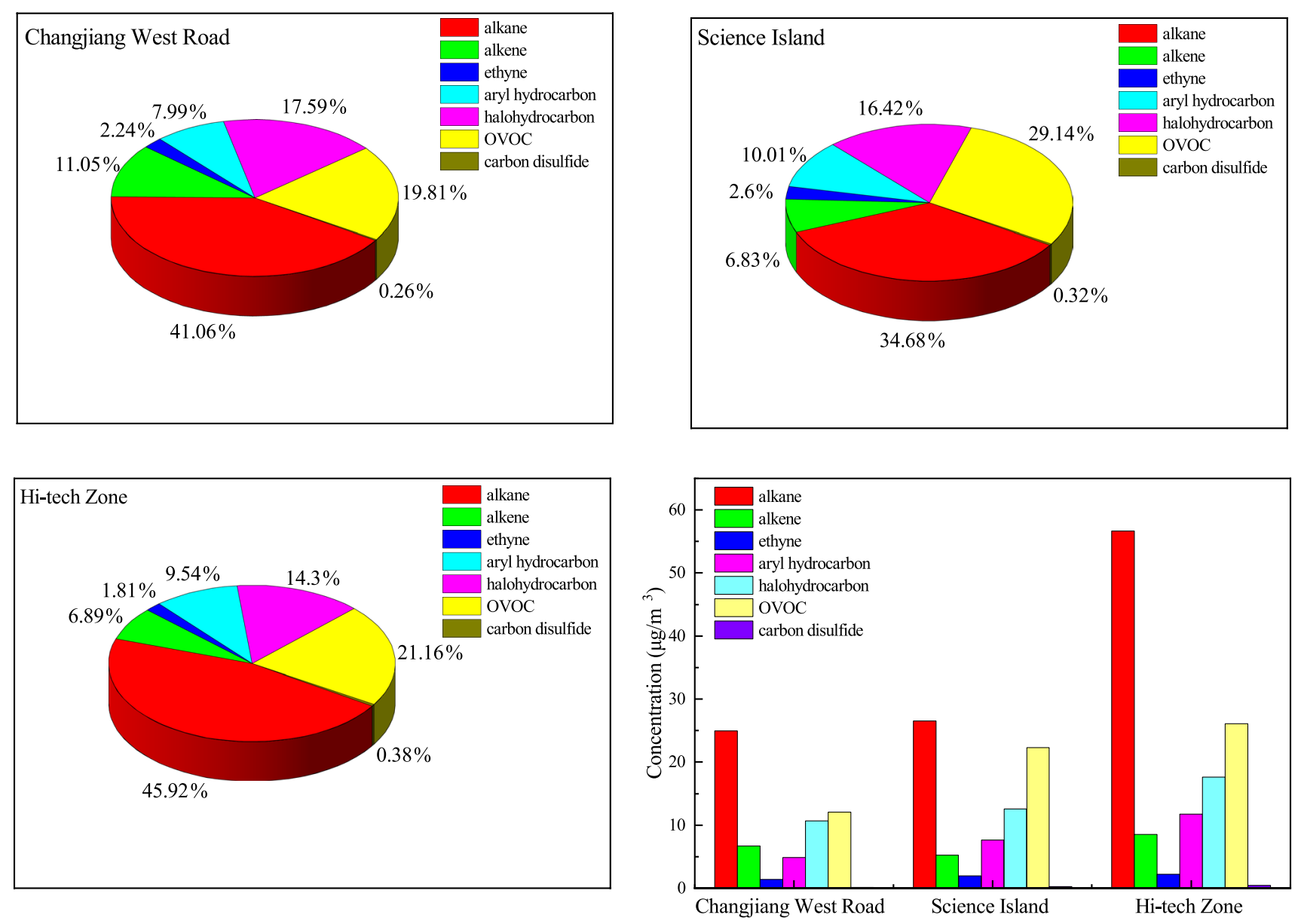

Fig. 4 Composition of VOCs in three sites

\section{Source appointment of VOCs}

Anthropogenic sources such as incomplete combustion of organic substances, the use of petrochemical solvents, and vaporizations of petroleum products are generally regarded as sources of VOCs (Baudic et al., 2016; Sillman, 1995). Source analysis of atmospheric VOCs at three sites in Hefei was carried out using PMF5.0 model. Figure 5 and Table 2 show the source component spectrograms of the PMF model at three sites, respectively. The Changjiang West Road site identified five major sources: automobile exhaust, gasoline volatilization, LPG volatilization, plant emissions, solvents, and coatings (Fig. 5a).

Based on the analysis of the PMF of the three observation points, the percentage of VOC contribution of the five sources indicates that the motor vehicle exhaust sources at the Changjiang West Road site account for the highest proportion, reaching $43.17 \%$. LPG volatile sources and volatile gasoline sources account for $19.06 \%$ and $18.76 \%$ respectively, followed by solvent and paint sources accounting for $12.20 \%$ and plant emission sources accounting for $6.80 \%$, respectively.

At the Science Island site, motor vehicle exhaust source accounts for the highest proportion, contributing $32 \%$ of VOC concentration, chemical solvent use source contributing 29\%, LPG volatile source and petrochemical source both contributing for about $17 \%$, while volatile gasoline source contributes less.

In the High-tech Zone site, gasoline vehicle emission sources contribute the highest proportion, contributing $40 \%$ to VOC concentration; chemical solvent use source, LPG volatile source, and material product industry contribute $19 \%, 18 \%$, and $17 \%$ of VOC concentration, respectively; and diesel vehicle emission sources contribute $6 \%$ of VOC concentration.

\section{Environmental impact of VOCs}

VOCs in different cities consist of hundreds of nonmethane hydrocarbons, and each of them has a different reaction rate, lifetime, and reaction mechanisms in the atmosphere. The mean OFP values of VOCs in the atmosphere of the three sites in Hefei are $136.70 \mu \mathrm{g} / \mathrm{m}^{3}, 138.18 \mu \mathrm{g} / \mathrm{m}^{3}$, and 
Fig. 5 PMF source component of sampling sites. a Yangtze West Road. b Science Island. c High-tech Zone
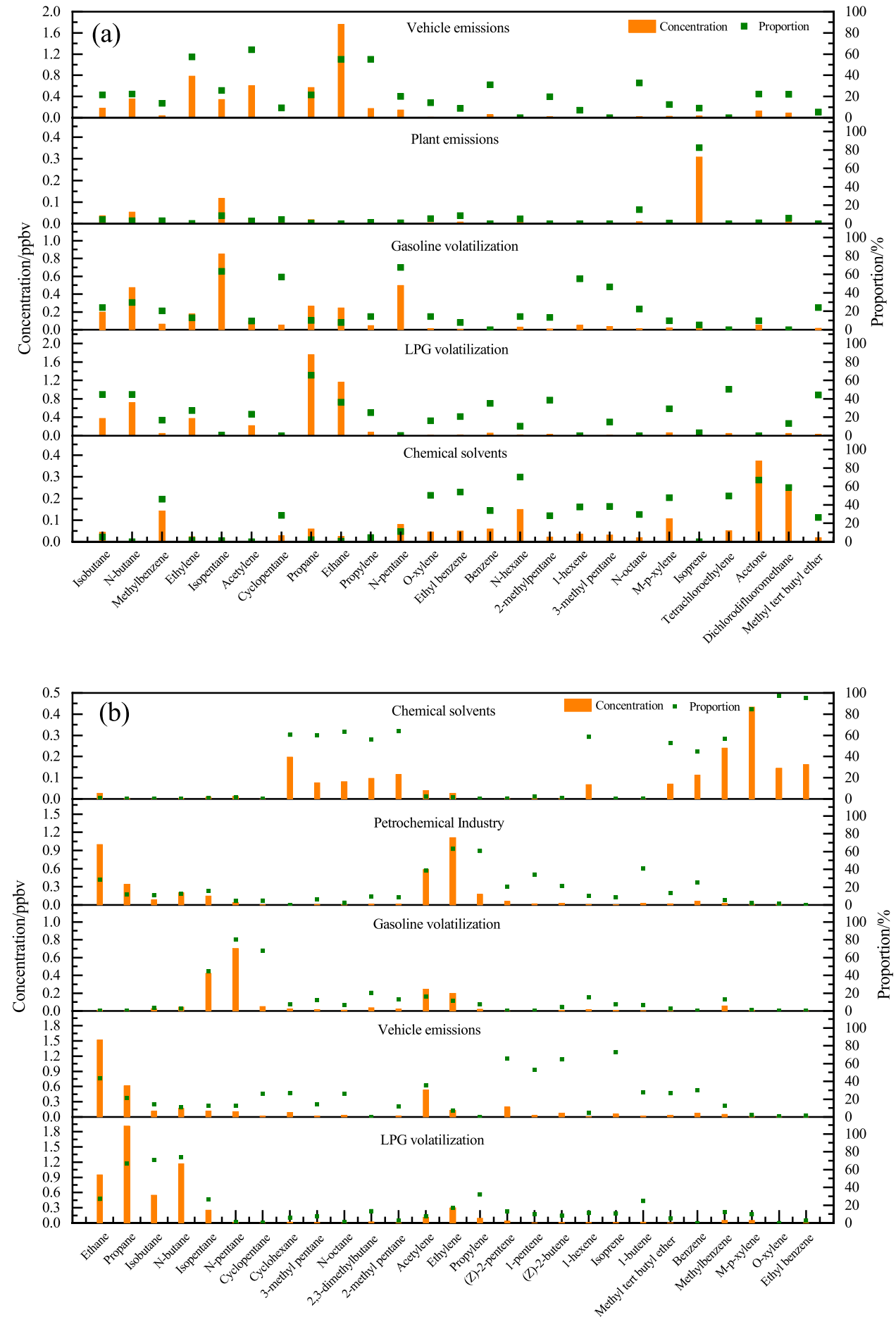

$229.40 \mu \mathrm{g} / \mathrm{m}^{3}$, respectively. This result is much lower than the measured results of Jinshan Industrial Zone in Shanghai, where the OFP of VOCs is about $421.3 \mu \mathrm{g} / \mathrm{m}^{3}$ (Zhang et al. 2018). The contribution of each VOC component to the OFP of the three sites is shown in Fig. 6 and Table 3. In the Changjiang West Road site, the alkenes and alkynes contribute the most significant proportion, followed by OVOCs, aromatics, alkanes, halogenated hydrocarbons, and others; alkenes are also Sanya's greatest contribution to OFP (Cao et al. 2021). The contribution ratio of alkenes and alkynes is the largest in the Science Island site, followed by aromatic hydrocarbon, OVOCs, alkane, halogenated hydrocarbon, and others. The High-tech Zone site has the highest proportion contributed by OVOCs, followed by alkenes, alkynes, aromatics, alkanes, halogenated hydrocarbons, and others. 
Fig. 5 (continued)

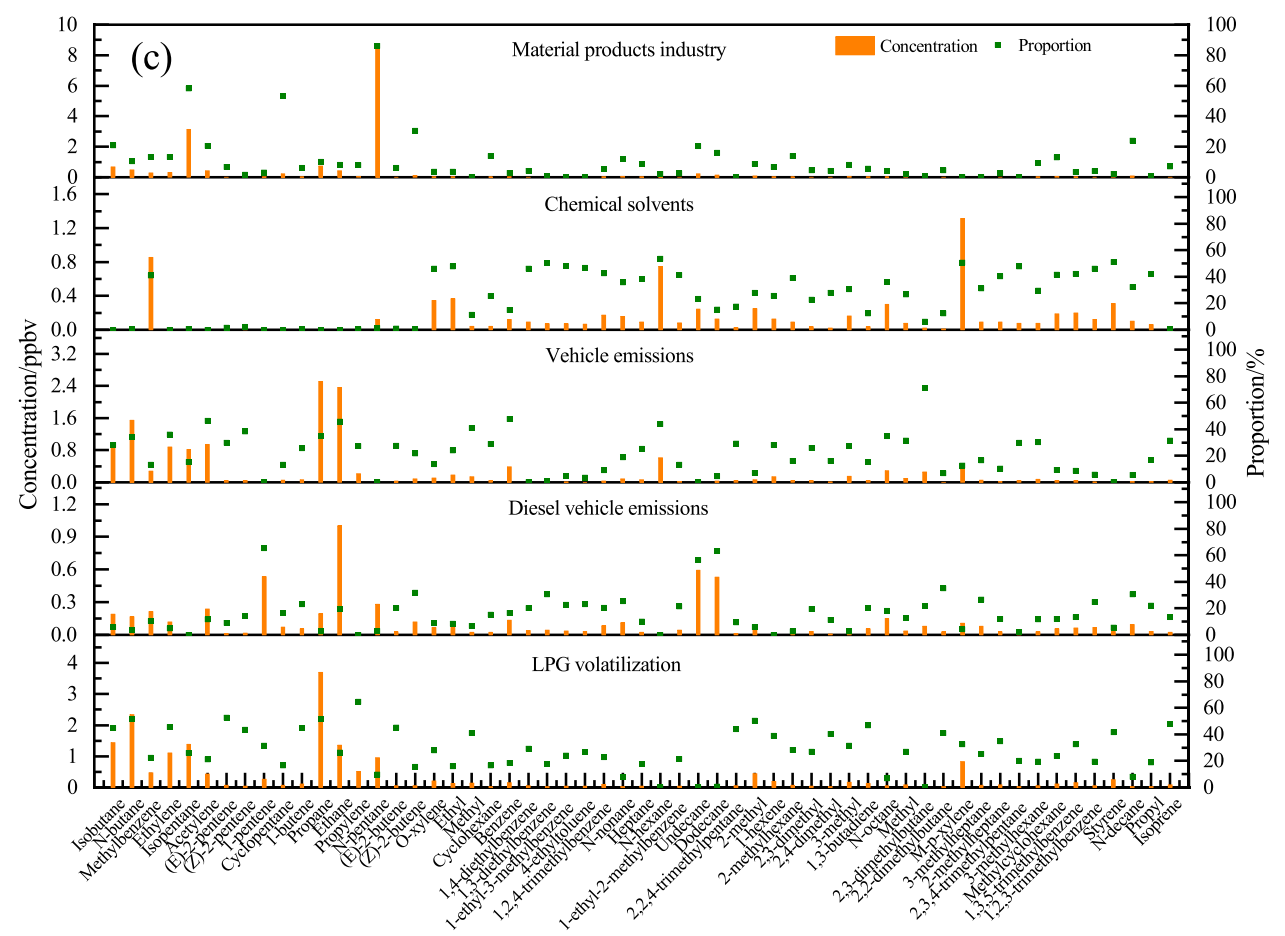

The mean value of $\mathrm{SOA}_{p}$ is $0.26 \mu \mathrm{g} / \mathrm{m}^{3}$ at the Changjiang West Road site, $0.33 \mu \mathrm{g} / \mathrm{m}^{3}$ at the Science Island site, and $0.50 \mu \mathrm{g} / \mathrm{m}^{3}$ at the High-tech Zone site. The main features here are the $\mathrm{SOA}_{p}$ values at all three sites are very small and the potential impact on $\mathrm{PM}_{2.5}$ concentration is very weak; the main species composition of the SOA generation potential is similar at all three sites, with aromatic hydrocarbons being the main contributor. This is different from the findings in Zhengzhou, where alkenes are the biggest contributor to ozone formation.

Table 2 The percentage (\%) of various sources contributing to VOCs through PMF analysis

\begin{tabular}{lcll}
\hline Source & $\begin{array}{l}\text { Yangtze } \\
\text { West Road } \\
\text { site }\end{array}$ & $\begin{array}{l}\text { Science } \\
\text { Island site }\end{array}$ & $\begin{array}{l}\text { High-tech } \\
\text { Zone site }\end{array}$ \\
\hline Motor vehicle exhaust source & 43.17 & 32 & - \\
Gasoline volatilization & 18.76 & 8 & 40 \\
LPG volatilization & 19.06 & 17 & 18 \\
Plant emissions & 6.80 & - & - \\
Solvents and coatings & 12.20 & - & \\
Chemical solvent use source & - & 29 & 19 \\
Petrochemical source & - & 17 & - \\
Diesel vehicle emissions & - & - & 6 \\
Material products industry & - & - & 17 \\
\hline
\end{tabular}

\section{Conclusion}

There are significant differences in VOC concentration among the three sites in Hefei, indicating that VOC concentration on an urban scale is more sensitive to local environment. Industrial park's VOC concentration is high and has more significant diurnal variations. The average concentration of VOCs in the city center is slightly lower but has a longer continuous time, with apparent composite pollution characteristics. The top 3 VOC components in Hefei are alkanes, OVOCs, and halogenated hydrocarbons, but the first components of the three sites are not the same, with the characteristics of urban scale heterogeneity. PMF analysis showed that traffic-related emission sources, such as motor vehicle exhaust, gasoline, and liquefied petroleum gas volatilization, contribute the most, followed by chemical solvent sources, material product industry, etc.

To sum up, the changes and composition source analysis of VOCs in Hefei City show that the concentration of VOCs in the urban atmosphere is closely related to local environmental conditions. The composition and source analysis reflect the emission characteristics of pollution sources to a certain extent. Therefore, analyzing the composition of VOCs in the urban atmosphere and its impact on the environment is helpful to identify the critical factors of regional pollution to implement targeted governance and improve air quality effectively. 
Fig. 6 Contribution of potential ozone generation of VOCs at different sites

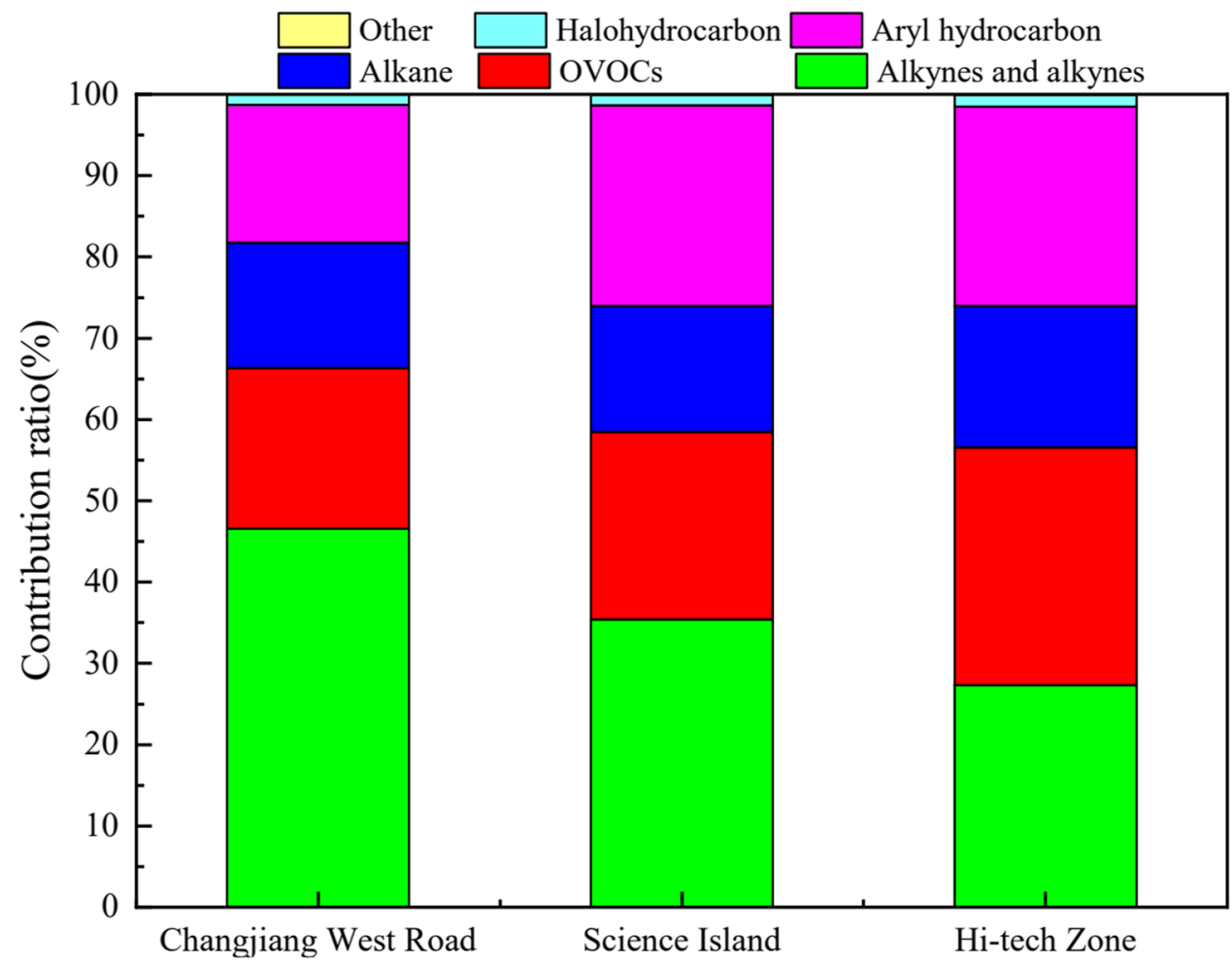

Table 3 The top OFP species and their proportions in sampling sites (\%)

\begin{tabular}{lccc}
\hline OFP species & $\begin{array}{l}\text { Yangtze West } \\
\text { Road site }\end{array}$ & $\begin{array}{l}\text { Science Island } \\
\text { site }\end{array}$ & $\begin{array}{l}\text { High-tech } \\
\text { Zone site }\end{array}$ \\
\hline Ethylene & 10.40 & 12.64 & 9.60 \\
Isoprene & 9.31 & 2.89 & - \\
cis-2-Pentene & 7.67 & 6.67 & 3.10 \\
Acetaldehyde & 6.02 & 5.40 & 5.80 \\
Propylene & 5.05 & 4.32 & 4.68 \\
M/P xylene & 4.74 & 8.87 & 8.21 \\
1-Amylene & 4.73 & - & 2.68 \\
Isopentane & 4.12 & - & 3.35 \\
Acrolein & 3.78 & 4.73 & - \\
Methylbenzene & 3.34 & 3.60 & 4.64 \\
n-Butanal & - & 4.10 & - \\
n-Butane & - & 3.13 & - \\
Acraldehyde & - & - & 3.26 \\
Propanal & - & - & 7.86 \\
\hline
\end{tabular}

Author contribution Wang completed the entire observation experiment, Yi analyzed the experimental data, and Liu completed the full text. All authors read and approved the final manuscript.

Funding This study was supported in part by grants from the Anhui Provincial Natural Science Foundation (2108085MD138), Research
Foundation of Anhui Jianzhu University (2020QDZ31) and the National Key Research and Development Plan (2018YFC0213800).

Data availability All data generated or analyzed during this study are included in this published article.

Code availability Not applicable.

\section{Declarations}

Ethics approval Not applicable.

Consent to participate Not applicable.

Consent for publication Not applicable.

Conflict of interest The authors declare no competing interests.

Open Access This article is licensed under a Creative Commons Attribution 4.0 International License, which permits use, sharing, adaptation, distribution and reproduction in any medium or format, as long as you give appropriate credit to the original author(s) and the source, provide a link to the Creative Commons licence, and indicate if changes were made. The images or other third party material in this article are included in the article's Creative Commons licence, unless indicated otherwise in a credit line to the material. If material is not included in the article's Creative Commons licence and your intended use is not permitted by statutory regulation or exceeds the permitted use, you will need to obtain permission directly from the copyright holder. To view a copy of this licence, visit http://creativecommons.org/licenses/by/4.0/. 


\section{References}

Baudic A, Gros V, Sauvage S, Locoge N, Sanchez O, Sarda-Estève R, et al (2016) Seasonal variability and source apportionment of volatile organic compounds (VOCs) in the Paris megacity (France). Atmos Chem Phys 29

Cao XC, Wu XC, Xu WS (2021) Pollution characterization, ozone formation potential and source apportionment of ambient VOCs in Sanya, China. Res Environ Sci

Carter W (1994) Development of ozone reactivity scales for volatile organic compounds. https://doi.org/10.1080/1073161X.1994.10467290

Cheng J, Su J, Cui T, Li X, Dong X, Sun F et al (2019) Dominant role of emission reduction in PM2.5 air quality improvement in Beijing during 2013-2017: a model-based decomposition analysis. Atmos Chem Phys 19(9):6125-6146. https://doi.org/10.5194/ acp-19-6125-2019

Dang R, Liao H, Fu Y (2021) Quantifying the anthropogenic and meteorological influences on summertime surface ozone in China over 2012-2017. Sci Total Environ 754:142394. https://doi.org/10. 1016/j.scitotenv.2020.142394

Grosjean D (1992) In situ organic aerosol formation during a smog episode: estimated production and chemical functionality. Atmos Environ A Gen Top 26(6):953-963. https://doi.org/10.1016/0960-1686(92)90027-I

Grosjean D, Seinfeld JH (1989) Parameterization of the formation potential of secondary organic aerosols. Atmos Environ (1967) 23(8):1733-1747. https://doi.org/10.1016/0004-6981(89)90058-9

Hatfield ML, Huff Hartz KE (2011) Secondary organic aerosol from biogenic volatile organic compound mixtures. Atmos Environ 45(13):2211-2219. https://doi.org/10.1016/j.atmosenv.2011.01.065

He C, Cheng J, Zhang X, Douthwaite M, Pattisson S, Hao Z (2019) Recent advances in the catalytic oxidation of volatile organic compounds: a review based on pollutant sorts and sources. Chem Rev 119(7):4471-4568. https://doi.org/10.1021/acs.chemrev.8b00408

Hui L, Liu X, Tan Q, Feng M, An J, Qu Y et al (2018) Characteristics, source apportionment and contribution of VOCs to ozone formation in Wuhan, Central China. Atmos Environ 192:55-71. https:// doi.org/10.1016/j.atmosenv.2018.08.042

Hui L, Liu X, Tan Q, Feng M, An J, Qu Y et al (2019) VOC characteristics, sources and contributions to SOA formation during haze events in Wuhan, Central China. Sci Total Environ 650:26242639. https://doi.org/10.1016/j.scitotenv.2018.10.029

Li K, Jacob DJ, Liao H, Shen L, Zhang Q, Bates KH (2019a) Anthropogenic drivers of 2013-2017 trends in summer surface ozone in China. Proc Natl Acad Sci 116(2):422-427. https://doi.org/10. 1073/pnas. 1812168116

Li K, Jacob DJ, Liao H, Zhu J, Shah V, Shen L et al (2019b) A two-pollutant strategy for improving ozone and particulate air quality in China. Nat Geosci 12(11):906-910. https://doi.org/10.1038/s41561-019-0464-x

Li Y, Yin S, Yu S, Bai L, Wang X, Lu X, Ma S (2021) Characteristics of ozone pollution and the sensitivity to precursors during early summer in central plain, China. J Environ Sci 99:354-368. https:// doi.org/10.1016/j.jes.2020.06.021

Liu B, Liang D, Yang J, Dai Q, Bi X, Feng Y et al (2016) Characterization and source apportionment of volatile organic compounds based on 1-year of observational data in Tianjin, China. Environ Pollut 218:757-769. https://doi.org/10.1016/j.envpol.2016.07.072

Liu X, Wang N, Lyu X, Zeren Y, Jiang F, Wang X et al (2021) Photochemistry of ozone pollution in autumn in Pearl River Estuary, South China. Sci Total Environ 754:141812. https://doi.org/10. 1016/j.scitotenv.2020.141812
Ma Z, Xu J, Quan W, Zhang Z, Lin W, Xu X (2016) Significant increase of surface ozone at a rural site, north of eastern China. Atmos Chem Phys 16(6):3969-3977. https://doi.org/10.5194/ acp-16-3969-2016

Mihriban YC, Tolga E, Remzi S et al (2015) Spatial and temporal variations in atmospheric VOCs, $\mathrm{NO}_{2}, \mathrm{SO}_{2}$, and $\mathrm{O}_{3}$ concentrations at a heavily industrialized region in Western Turkey, and assessment of the carcinogenic risk levels of benzene. Atmos Environ 103:102-113

Niu Z, Kong S, Zheng H, Yan Q, Liu J, Feng Y et al (2021) Temperature dependence of source profiles for volatile organic compounds from typical volatile emission sources. Sci Total Environ 751:141741. https://doi.org/10.1016/j.scitotenv.2020.141741

Norris G, Duvall R, Brown S, Bai S (2014) EPA positive matrix factorization (PMF) 5.0 fundamentals and user guide, 136

Shao M, Zhang Y, Zeng L, Tang X, Zhang J, Zhong L, Wang B (2009) Ground-level ozone in the Pearl River Delta and the roles of VOC and NOx in its production. J Environ Manage 90(1):512-518. https://doi.org/10.1016/j.jenvman.2007.12.008

Wang Y, Liao H (2020) Effect of emission control measures on ozone concentrations in Hangzhou during G20 meeting in 2016. Chemosphere 261:127729. https://doi.org/10.1016/j.chemosphere. 2020.127729

Wei W, Li Y, Wang Y, et al (2018) Characteristics of VOCs during haze and non-haze days in Beijing, China: concentration, chemical degradation and regional transport impact. Atmos Environ 194(DEC.):134-145

Xue Y, Ho SSH, Huang Y, Li B, Wang L, Dai W et al (2017) Source apportionment of VOCs and their impacts on surface ozone in an industry city of Baoji, Northwestern China. Scientific Reports 7(1):9979. https://doi.org/10.1038/s41598-017-10631-4

Yang Y, Liu X, Zheng J, Tan Q, Feng M, Qu Y et al (2019) Characteristics of one-year observation of VOCs, NOx, and $\mathrm{O} 3$ at an urban site in Wuhan, China. J Environ Sci 79:297-310. https://doi.org/ 10.1016/j.jes.2018.12.002

Yue X, Unger N, Harper K, Xia X, Liao H, Zhu T et al (2017) Ozone and haze pollution weakens net primary productivity in China. Atmos Chem Phys 17(9):6073-6089. https://doi.org/10.5194/ acp-17-6073-2017

Yurdakul S, Civan M, Kuntasal Z et al (2018) Temporal variations of VOC concentrations in Bursa atmosphere [J]. Atmos Pollut Res 9(2):189-206

Zeng Y, Cao Y, Qiao X, Seyler BC, Tang Y (2019) Air pollution reduction in China: recent success but great challenge for the future. Sci Total Environ 663:329-337. https://doi.org/10.1016/j.scito tenv.2019.01.262

Zou Y, Deng XJ, Zhu D, Gong DC, Wang H, Li F et al (2015) Characteristics of 1 year of observational data of VOCs, $\mathrm{NO}_{x}$ and $\mathrm{O}_{3}$ at a suburban site in Guangzhou, China. Atmos Chem Phys 15(12):6625-6636. https://doi.org/10.5194/acp-15-6625-2015

Zhang Y, Li R, Fu H, et al (2018) Observation and analysis of atmospheric volatile organic compounds in a typical petrochemical area in Yangtze River Delta, China. J Environ Sci

Publisher's note Springer Nature remains neutral with regard to jurisdictional claims in published maps and institutional affiliations. 